\title{
Arqueología andina: nuevos actores y análisis
}

En este NúMERo de ALLPANCHIS SE OfRECEN ARTíCulos que se ocupan — de modo original en la arqueología peruana, que suele centrar sus esfuerzos en las civilizaciones y culturas durante el periodo prehispánico- de actores y espacios aún no suficientemente analizados. La población africana en las haciendas virreinales, las islas del mar peruano y el segundo asentamiento de la ciudad española de San Miguel de Piura son los temas que ocupan a los colaboradores de este número dedicado a la arqueología andina.

En las primeras tres contribuciones que conforman el número temático se aprecia cómo el empleo simultáneo de metodologías e interpretaciones de la arqueología, la etnohistoria y la historia ofrece nuevos resultados y argumentaciones más sólidas para la reconstrucción del pasado. Esta tendencia interdisciplinaria es válida tanto para su aplicación a la época previa al arribo de los conquistadores españoles como al periodo virreinal. Con todo ello, se espera que la presente edición de Allpanchis despierte la atención hacia actores sociales poco atendidos en la historiografía peruana y demuestre lo valioso de emplear nuevos análisis para mirar el pasado. 
El primer texto aborda una inmensa y, en cierta medida, desconocida área acuática: el mar peruano y sus islas, buscando señalar puntos trascendentales a lo largo de un espacio de tiempo de casi dos milenios. Vicente Cortéz y Carlos Ausejo exponen, con base en investigaciones arqueológicas, etnohistóricas e históricas, los diversos significados, valores y usos de las islas e islotes del litoral: los que alguna vez conformaron espacios sagrados entre el mundo de los vivos y de los ancestros en la etapa prehispánica fueron, en cierta medida, afectados tras la conquista española. El caso del indígena Pedro Guañeque, principal del valle de Chincha a mediados del siglo XVI sirve para mostrar esos cambios. En otro momento, ya en la centuria xix, los autores resaltan el papel de las islas como estaciones en rutas oceánicas y fuentes de un recurso natural de amplia demanda en el mercado internacional —el guano de isla- y, para las centurias restantes, como zonas para el trabajo de campo arqueológico, áreas de protección ecológica y atracciones turísticas.

Por su parte, el artículo de Fernando Vela Cossío explora uno de los yacimientos urbanos más importantes del momento virreinal temprano: la ciudad de San Miguel (actual Piura). Considerada la primera ciudad española en América del Sur, sufrió — tras su fundación original en 1532 - un primer traslado a la zona del Alto Piura en 1534, donde se consolidó como un emplazamiento estratégico para las campañas de conquista hasta su abandono, en 1580. Los resultados de las excavaciones arqueológicas selectivas y del análisis documental de fuentes de la época han permitido al autor esbozar nuevas explicaciones para el traslado y abandono de este emplazamiento hispano. De la misma manera, el arqueólogo detalla la posible expansión urbanística y desarrollo arquitectónico experimentado en Piura la Vieja.

El trabajo de Brendan Weaver plantea, inicialmente, un cuestionamiento al tradicional enfoque de los estudios sobre la población africana virreinal y propone que la arqueología histórica puede ofrecer nuevas aproximaciones al tema. Con metodologías propias 
de esta disciplina, Weaver ha venido trabajando la presencia africana en dos haciendas jesuitas del valle de Nasca (San Joseph y San Xavier) durante los siglos XVII y XVIII. En ellas ha podido reconstruir no solo el sistema laboral y administrativo de las estancias, sino también su ocupación espacial, algunas prácticas relacionadas a la vida doméstica y la pervivencia de ciertas tradiciones que escaparon a la documentación oficial.

Siguiendo con los escritos que completan este número de Allpanchis, Aude Argouse, a través de la observación de los actos testamentarios, reconstruye un aspecto novedoso de la vida social y cultural de Cajamarca durante el siglo XVII. La doctora en Historia observó un fenómeno sui géneris: la alta presencia del apellido Lachos, utilizado para designar a mujeres «indias». Argouse logra establecer una relación entre estas mujeres y los miembros de la élite indígena no inca de Cajamarca a quienes dispensaron un «apoyo discreto» en las disputas contra el grupo de españoles que buscaba legitimar su presencia en dicha región de la sierra norte del virreinato peruano. En una sociedad donde las mujeres podían heredar los cacicazgos, mas no ejercer el cargo, la reputación de un apellido ayudaba a mantener el derecho a heredar y transmitir el mencionado curacazgo.

Carlos Arrizabalaga examina y traduce al español, en esta entrega, tres reportajes firmados por la periodista estadounidense Fannie B. Ward a fines del siglo xix sobre la ciudad del Cusco y otros sitios de valor histórico de su rededor, que fueron dados a conocer en diversos periódicos de su país natal. Con información biográfica acerca de su experiencia laboral, sus viajes por Latinoamérica y sus vínculos interpersonales, el autor español devela retratos de la vida profesional de Ward y de la situación de la prensa norteamericana del periodo decimonónico tardío. Conocemos cómo la periodista, que desarrollaba su labor como freelance, vio en los reportes de viajes al extranjero la forma de desarrollarse dentro del periodismo dominado por varones. 
La última contribución presentada pertenece a Deyvi Saavedra Ordinola, quien estudia el proceso de surgimiento del primer panteón extramuros en el pueblo de Ayaviri (Puno) y su inserción en la colectividad. En el lapso elegido, que va desde 1830 a 1940, se detectan cambios, pero también continuidades en la actitud de los pobladores, mayoritariamente indígenas, hacia la muerte. Empleando fuentes escritas de la época (libros de fábrica y de entierros de la parroquia ayavireña, y testamentos) y testimonios orales contemporáneos, el autor, en una primera presentación de datos, resalta aspectos locales como el cambio de un espacio interior y sagrado como un templo religioso- - a uno exterior, al aire libre y de grandes dimensiones «sin mayor carácter religioso» y con nuevas demandas.

Poder presentar este número de Allpanchis ha significado contar con el apoyo reiterado de colaboradores en los diferentes momentos del proceso de edición. Sin duda, especial agradecimiento va dirigido a la autora y autores que contribuyeron con la presente publicación así como a los evaluadores. Consultas muy precisas para el desarrollo de este dossier pudieron ser resueltas gracias a la orientación de arqueólogos como Antonio Coello, Alexander Herrera y Markus Reindel, a quienes sentidamente agradecemos.

Carlos Zegarra Moretti 